\title{
Avaliação de defeitos no processo de fabricação de lamelas para pisos de madeira engenheirados com uso de ferramentas de controle de qualidade
}

\author{
Jaqueline COLETTI ${ }^{1}$, Ghislaine Miranda BONDUELLE², Setsuo IWAKIRI ${ }^{3}$
}

\begin{abstract}
RESUMO
Os defeitos das lamelas são responsáveis em grande parte pelo retrabalho, perdas e diminuição da qualidade do piso acabado. Esses defeitos geram aumento de custos de produçáo sendo um fator muito importante para o processo de fabricação de pisos de madeira. Este trabalho tem por objetivos classificar e quantificar os defeitos ocorrentes na produçáo de lamelas, buscar causas, propor soluçóes e melhorias através da aplicação de ferramentas de qualidade como: "Brainstorming", "Diagrama de Pareto", "Diagrama de Ishikawa” e 5W2H . Foram amostrados 1598,47 $\mathrm{m}^{2}$ de lamelas das seguintes espécies: Muiracatiara (Astronium lecointei Ducke), amendoim (Pterogyne nitens Tul), cabreúva ((Myroxylon Balsamum Harms) e timborana (Pseudopiptadenia suaveolens Miq) com as seguintes dimensōes: espessuras $(2,5 \mathrm{~mm}$ e $3,5 \mathrm{~mm})$, larguras $(76,2 \mathrm{~mm}, 82,5 \mathrm{~mm}$ e $127 \mathrm{~mm})$, comprimentos $(450 \mathrm{~mm}$ a $1.200 \mathrm{~mm})$. O defeito mais freqüente encontrado na produção de lamelas foi a marca de serra (31\%), seguido de corte da madeira feito pelo fornecedor (23\%) e falta de instrução de trabalho (15\%). As principais causas dos defeitos de marca de serra são devidas aos problemas de manutenção de serras da empresa fornecedora de madeira.
\end{abstract}

PALAVRAS-CHAVE: lamelas, pisos laminados, controle de qualidade.

\section{Evaluation of the production process of lamella for engineered wood floor using quality control instruments}

\begin{abstract}
Lamella defects are responsible in large part for rework losses and decrease in the quality of the finished floor. These defects increase costs, a very important factor in the process wood floor production. This work aimed to quantify and classify the common defects occurring in the lamella production, find out causes and propose solutions and improvements using the tools "Brainstorming", "Pareto Diagram", "Ishibawa Diagram", and 5W2H. 1598,47 square meters of lamella of the species Muiracatiara (Astronium lecointei Ducke), Amendoim (Pterogyne nitens Tul), Cabreúva (Myroxylon Balsamum Harms) and Timborana (Pseudopiptadenia suaveolens Miq) were sampled with the following dimensions: thickness $(2.5 \mathrm{~mm}$ and $3.5 \mathrm{~mm})$, width $(76,2 \mathrm{~mm}, 82,5 \mathrm{~mm}$ and $127 \mathrm{~mm})$, lenght $(450 \mathrm{~mm}$ to $1.200 \mathrm{~mm})$. The most frequent defect found at the lamella production was the mark of the saw (31\%), followed by the wood cut done by the supplier (23\%) and the lack of work instructions $(15 \%)$. The main causes to the mark of the saw were the defects caused by saw maintenance problems of the wood suppliers.
\end{abstract}

KEYWORDS: face layer, engineered floorings, quality control

1 Universidade Federal do Paraná - UFPR. E-mail: jaquecoletti@hotmail.com

2 Universidade Federal do Paraná - UFPR. E-mail: ghislaine@ufpr.br

${ }^{3}$ Universidade Federal do Paraná - UFPR. E-mail: setsuo@ufpr.br 


\section{INTRODUÇÃO}

A globalizaçáo da economia levou ao acirramento da concorrência entre as empresas de base florestal. Cada qual passa a se preocupar e a tomar decisóes no sentido de buscar o máximo de aproveitamento da matéria-prima disponível e otimização do processo produtivo. Os objetivos das empresas passam a ser redução no custo de produção e melhoria da qualidade do produto, fatores estes, decisivos na competitividade das empresas no mercado.

A produção de pisos de madeira no Brasil vem crescendo expressivamente a partir de meados da década de 90 , tendo alcançado em 2006 cerca de 33 milhóes de $\mathrm{m}^{2}$, sendo que quase $75 \%$ dessa produção correspondem aos "pisos engenheirados" (ABIMCI, 2007).

O termo "piso engenheirado" é de uso recente, o qual é um produto fabricado a partir de painéis compensados multilaminados ou painéis de fibras de alta densidade (HDF - high density fiberboard) revestidos com lâminas decorativas de madeira ou papéis melamínicos. No processo de fabricação de "pisos engenheirados" laminados, são utilizadas lâminas de madeiras coladas como em painel compensado, formando a base do piso. $\mathrm{Na}$ fase seguinte, o compensado passa por um processo de calibraçáo e lixamento para ajuste da espessura, sendo esse processo importante para receber a camada de lâminas de madeiras decorativas na face. A fase final consiste de cortes longitudinais em larguras finais do piso, perfilamento longitudinal e transversal para encaixes e aplicação de material de acabamento superficial (Iwakiri et al., 2006).

Os "pisos engenheirados", por serem produtos colados de madeira, apresentam uma série de vantagens em relaçấo aos pisos de madeira maciça. A principal delas é resultante da composição estrutural do painel compensado que utiliza o princípio da laminação cruzada, aliada à restrição imposta pela linha de cola às diferentes alteraçôes dimensionais das camadas adjacentes, resultando em produto com maior estabilidade dimensional, quando comparado ao piso de madeira maciça sob influência do fator anisotrópico (Tsoumi, 1991; Sellers, 1993).

A base do piso engenheirado é constituída de painel compensado fabricado com lâminas de madeiras de alta densidade, conferindo ao material alta resistência e estabilidade dimensional e que não empenam mediante as variaçóes de umidade e temperatura dos ambientes. Quando é utilizada a madeira maciça na face do piso, o painel é seccionado longitudinalmente em "réguas" e revestido no estrato superior (capa) com lamelas selecionadas de madeiras nobres. Após a colagem, a peça é calibrada, recortada e a capa recebe o tratamento com vernizes especiais, resistentes ao tráfego e que salientam a beleza natural da madeira.
Os principais tipos de defeitos observados no processo de produçấo de "pisos engenheirados" são as espessuras e teor de umidade fora de padróes especificados, tanto para lâminas que iráo compor a base, quanto para madeira serrada utilizada para lamelas. Esses defeitos irão comprometer a colagem e acabamento superficial dos pisos resultando em custos de desclassificaçáo do produto final. Por outro lado, o conhecimento técnico adequado da matéria-prima pode maximizar seu potencial de uso e minimizar os problemas no controle dos parâmetros do processo produtivo.

De acordo com Juran \& Gryna (1991) um programa de qualidade, adequadamente elaborado e executado, deve proporcionar melhorias significativas em termos de eficiência, segurança, controle de qualidade e desempenho da gestáo. Esse programa bem definido, seria uma enorme contribuição para as empresas produtoras de pisos de madeira que estâo buscando os caminhos corretos para o desenvolvimento do setor.

Algumas ferramentas são essenciais para a boa execução do programa, conforme descrito por Bonduelle (2007) a seguir:

- O Brainstorming ou tempestade cerebral: é uma ferramenta que auxilia as pessoas a produzirem idéias para a resolução de um problema;

- O Gráfico de Pareto: técnica para registrar e analisar informaçóes que permitem a priorizaçáo da tomada de decisão. A utilização desse gráfico é muito interessante porque sugere em quais os erros ou atividades ou recursos devem ser concentradas prioritariamente as açôes de melhoria;

- O Gráfico de Ishikawa ou Espinha de Peixe: Técnica utilizada para auxiliar na identificação de possíveis causas de um problema, mas também, pode ser usada para a melhoria de alguma atividade ou recursos;

- Método 5W2H: Ferramenta de análise cujo objetivo é direcionar a discussão em um único foco, evitando a dispersão das idéias. È uma ferramenta útil em duas situações distintas de análise: (a) Verificação da ocorrência de um problema, e (b) Elaboração de um Plano de Ação.Esse método também é chamado de 6M's no qual agrupam-se os assuntos por "famílias": Mão-de-obra, máquina, material, método, medidas e meio-ambiente.

Dentre os benefícios pode-se destacar: agregação de valor aos produtos de madeira, garantia de qualidade, incremento nas vendas e desenvolvimento geral do setor.

Os defeitos das lamelas são responsáveis em grande parte pelo re-trabalho, perdas e diminuição da qualidade do piso acabado. Esses defeitos geram aumento de custos de produção sendo um fator muito importante para o processo de fabricação de pisos de madeira. Ao se conhecer processos 
e causas dos defeitos citados, torna-se mais fácil amenizar ou até mesmo eliminar tais defeitos originados.

Este trabalho foi desenvolvido com os seguintes objetivos:

- Identificar os defeitos na produção de lamelas de madeira destinadas a fabricação de pisos de forma qualitativa e quantitativa;

- Avaliar o nível de ocorrência dos defeitos nas espécies estudadas;

- Buscar as causas desses defeitos;

- Propor um plano de açáo para a eliminação dos defeitos e prevençáo da sua re-ocorrência.

\section{MATERIAL E MÉTODOS}

MATERIAL

O material objeto deste estudo foi madeira serrada de espécies tropicais utilizado como lamelas na fabricação de "pisos engenheirados", ou ainda, conceituados como "pisos estruturados de madeira" e "pisos multilaminados de madeira”, que são materiais de revestimentos conhecidos internacionalmente de "engineered flooring".

As espécies estudadas foram: Muiracatiara (Astronium lecointei Ducke), Amendoim (Pterogyne nitens Tul), Cabreúva (Myroxylon Balsamum (Harms) e Timborana (Pseudopiptadenia suaveolens Miq). As lamelas foram avaliadas depois de processadas e classificadas, com as espessuras de 2,5 e $3,5 \mathrm{~mm}$, largura de $76,2 \mathrm{~mm}, 82,5 \mathrm{~mm}$ e $127 \mathrm{~mm}$ e comprimentos de $450 \mathrm{~mm}$ a $1.200 \mathrm{~mm}$.

\section{PROCESSO DE PRODUÇÃO DE LAMELAS PARA PISO ENGENHEIRADO}

O processo de produção de lamelas para "piso engenheirado" inicia-se com o recebimento e inspeção de qualidade da madeira na forma de serrados. Após a inspeção, a madeira é processada numa plaina S2S para calibraçáo da espessura e gradeada para ser submetido ao pré-secador por aproximadamente 20 dias para remoção do excesso de umidade. A secagem final é realizada numa estufa convencional com programa de secagem estabelecido em função da espécie de madeira e até o teor de umidade final pré-estabelecido.

Após a secagem, a madeira passa por um processo de climatização por 72 horas e por re-processamento numa refiladeira e plaina quatro faces $(\mathrm{S} 4 \mathrm{~S})$. Na seqüência, as peças aplainadas são seccionadas numa serra otimizadora para ajuste dos comprimentos nas seguintes medidas adotadas pela empresa: $450 \mathrm{~mm} ; 525 \mathrm{~mm} ; 600 \mathrm{~mm} ; 675 ; 750 \mathrm{~mm} \mathrm{e}$ $1.200 \mathrm{~mm}$.

$\mathrm{Na}$ etapa seguinte, as peças são processadas numa serra múltipla para obtenção de lamelas. $\mathrm{O}$ processo se finaliza com a calibração da espessura e classificação das lamelas para colagem como estrato superior do piso engenheirado.

\section{METODOLOGIA DE PESQUISA}

\section{COLETA DE DADOS}

A coleta de dados consistiu em obtenção de duas informaçóes básicas inerentes a espessura das lamelas e determinação das classes de qualidade em função de defeitos superficiais das lamelas; Para a composição deste trabalho foram medidas e classificadas $1.598,47 \mathrm{~m}^{2}$.

\section{APLICAÇÃO DE FERRAMENTAS DA QUALIDADE NO CONTROLE DO PROCESSO}

\section{DIAGRAMA DE PARETO}

Os defeitos encontrados foram analisados através do gráfico de Pareto, onde este prioriza a tomada de decisão.

O diagrama de Pareto é uma forma especial do gráfico de barras verticais, que nos permite determinar quais problemas resolver e qual a prioridade, além de permitir que se estabeleçam metas numéricas viáveis a serem alcançadas. É elaborado com base em uma folha de verificação e/ou em uma outra fonte de coleta de dados, que nos ajuda a dirigir atenção e esforços para priorizar as causas vitais.

\section{ANÁLISE DOS FATORES QUE CAUSAM OS PROBLEMAS}

Após os defeitos serem elencados é necessário descobrir quais os fatores que estão causando as anomalias antes de propor correçóes e melhorias. Algumas ferramentas da qualidade podem ajudar a manter o foco na busca encontrando a causa fundamental do problema com conseqüente aplicação de uma solução definitiva. Optou-se pela aplicação de ferramentas simples e de resultados imediatos, as quais são descritas a seguir:

a) Brainstorming - conhecida com "tempestade de idéias", é mais que uma técnica de dinâmica de grupo é uma atividade desenvolvida para explorar a potencialidade criativa do indivíduo, colocando-a a serviço de seus objetivos.

A técnica é dividida em três partes:

- Encontrar os fatos;

- Geração de idéia;

- Encontrar solução.

Da busca dos fatos na resolução de um problema existem duas sub-partes:

- Definição do problema;

- Preparação.

Inicialmente, define-se o problema. Poderá ser necessário subdividir o problema em várias partes. A técnica de Brainstorming funciona para problemas que têm muitas soluçóes possíveis tal como a geração de idéias para o seu 
desenho. Depois é necessário colher toda a informação que pode relacionar-se com o problema. Geraçáo de idéias por brainstorming, busca da solução, avaliação e seleção das melhores idéias.

b) Diagrama de Ishikawa - a metodologia proposta no gráfico de Ishikawa segue as seguintes etapas:

- Definição do efeito: algumas vezes, o efeito é um problema, como "erros em pedidos"; outras vezes é alguma coisa que necessita ser descrita em termos de qualidade, como "desenvolver o melhor treinamento em motivação gerencial";

- Geração de idéias: "Brainstorming" é uma maneira de um grupo gerar muitas idéias em um curto espaço de tempo;

- Identificação da principal categoria: baseado na lista de idéias, gerarem uma lista de categorias. Reduzir o número de categorias, se algumas são comuns a outras. Verificar se as idéias se ajustam dentro das categorias estabelecidas. $\mathrm{O}$ diagrama de causa e efeito não pode ter mais de 5 a 7 categorias.

- Avaliação das idéias: a avaliação pode conter a explanação de idéias, o agrupamento das que está fortemente relacionado, ou sua eliminação. A avaliação visa àquele que deu a sugestão, porque a idéia agora pertence ao grupo.

- Projeção da folha para a coleta de dados: baseado no diagrama de causa e efeito e nas causas potenciais do problema, registra numa folha de coleta de dados, as informaçôes para validar a causa real.

Os diagramas de causas e efeitos identificam apenas causas possíveis, somente os dados indicarão as causas reais. Quando o diagrama de causa e efeito é utilizado para fins de planejamento, concentre a atenção sobre um resultado desejado. A seta principal aponta para o efeito desejado e as setas menores dos ramos representam vários meios necessários para alcançar o resultado.

c) $5 \mathrm{~W} 2 \mathrm{H}$ - O uso desta ferramenta tem-se mostrado eficiente para ajudar na resolução das causas fundamentais e seu desdobramento pode ser resumido como segue (Campos,1994):

- WHAT - (O QUÊ?): definem-se as tarefas que serão realizadas seguindo o plano de execução. "O quê será feito?";

- WHEN - (QUANDO?): estabelece-se um cronograma detalhado dos prazos para o cumprimento das tarefas. "Quando será feito?";

- WHO - (QUEM?): determinam-se quais serão as pessoas responsáveis pelas tarefas. "Quem fará?";

- WHERE - (ONDE?): define-se em que local as tarefas serão realizadas. "Onde será feito?";

- WHY - (POR QUÊ?): significa a razão pela quais as tarefas devem ser executadas. "Por quê será feito?";
- HOW - (COMO?): traça-se as maneiras mais racionais e econômicas de executar as tarefas. "Como será feito?";

- HOW MUCH - (QUANTO CUSTA?): determina-se quais serão os custos para a realização das tarefas. "Quanto custa o que será feito?”.

\section{RESULTADOS E DISCUSSÃO}

Entre as espécies de madeiras estudadas os defeitos encontrados nas lamelas foram: marcas de serras, buracos, rachaduras, empenamento, encanoamento, ponta quebrada, espessura, largura e comprimento desiguais.

A maior ocorrência de defeito entre todas as espécies avaliadas foi a marca de serra nas faces das lamelas. Na Figura 01 estáo apresentados os resultados das avaliaçóes.

De acordo com a Figura 1, pode-se observar que a maior percentagem de defeitos encontrados foi para a marca de serra, o qual representa quase $50 \%$ do total. Na seqüência, foram obtidos por ordem decrescente de freqüência os seguintes tipos de defeitos: rachadura, empenamento, buracos, largura, encanoamento, espessura, ponta quebrada e comprimento.

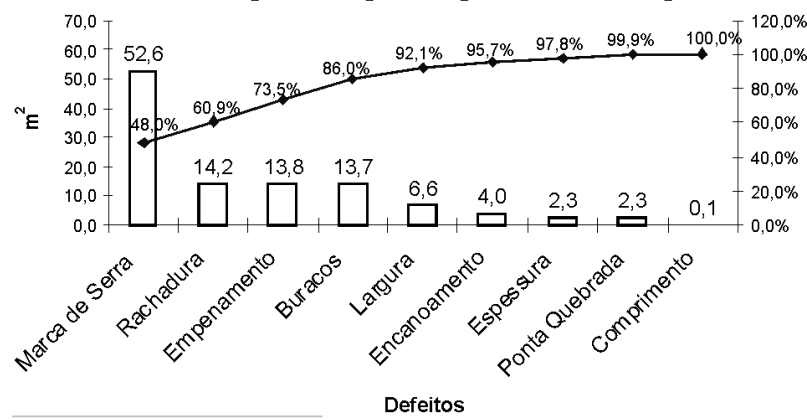

Figura 1 - Gráfico de Pareto para os principais tipos de defeitos encontrados.

Bonduelle (1996) observa que somente $20 \%$ das causas são responsáveis por $80 \%$ dos problemas nas organizaçóes. Nesse caso tem-se a marca de serra, rachadura e empenamentos, responsáveis por $86 \%$ dos defeitos no processo deverão ser o foco de açóes corretivas e/ou preventivas.

$\mathrm{Na}$ Figura 2, encontra-se ilustrado o principal tipo de defeito nas lamelas - a marca de serra.

O gráfico de Pareto apresentado na Figura 3 mostra o percentual de ocorrência de marca de serra nas lamelas das espécies estudadas.

Os resultados da Figura 3 indicam maiores percentuais de ocorrências de marca de serra na lamela das espécies de "amendoim" e "timborana", correspondendo a 93,2\% do total de ocorrências. As lamelas da madeira de "cabreúva" apresentaram níveis abaixo de $1 \%$ de defeitos de marca de serra.

Após a fase de identificação e quantificação dos defeitos em lamelas foi realizado um Brainstorming para indicação das 


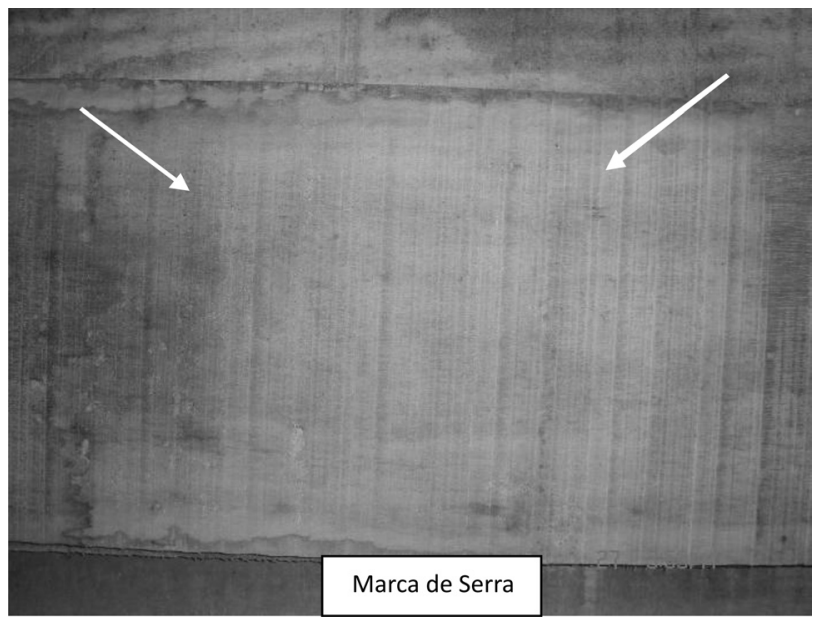

Figura 2 - Marca de serra na lamela.

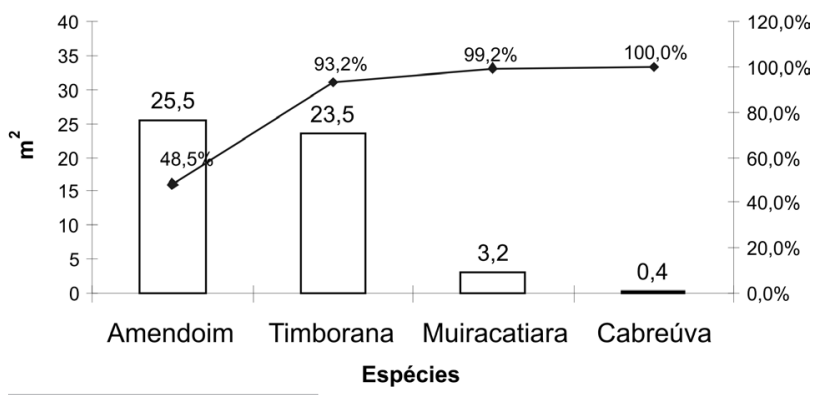

Figura 3 - Gráfico de Pareto com incidência de marca de serra por espécie. possíveis causas da marca de serra encontradas nas lamelas estudadas. Foi aplicado o diagrama de Ishikawa e de um plano de ação $5 \mathrm{~W} 2 \mathrm{H}$, onde buscou se detectar a causa da ocorrência desse defeito e indicar açôes corretivas para solução deste defeito.

\section{BRAINSTORMING}

Inicialmente, foi definido o problema, o qual foi subdividido em varias partes. A seguir, foram coletadas todas as informaçôes que poderiam estar relacionadas com o problema. Foram avaliadas as possíveis solucôes e a melhor proposta. O resultado do Brainstorming encontra-se listado na Tabela 01 .

Os resultados demonstram que a empresa precisa avaliar melhor os seus fornecedores e providenciar açóes corretivas em conjunto visando a eliminação deste problema, pois $54 \%$ das marcas de serra são originadas no fornecedor. Dois outros defeitos que chamam a atenção são a falta de instrução de trabalho e falha na inspeção visual, com $30 \%$ de ocorrências. Problemas estes que estáo relacionados ao treinamento de inspetores que recebem a madeira dos fornecedores. As outras duas ocorrências referem-se à conservação e manutenção da serra com 16\%. Estas causas são de fácil solução, tendo em vista a possibilidade de exigência junto à empresa fornecedora de madeira para melhor manutenção das serras que são ferramentas essenciais para operaçóes de corte.

\section{DIAGRAMA DE ISHIKAWA}

$\mathrm{Na}$ Figura 4 encontra-se ilustra a aplicação do Diagrama de Ishikawa para o principal tipo de defeito que é a marca de serra.

O resultado da busca de causas pelo Diagrama de Ishikawa confirma que a marca de serra encontrada nas lamelas é, principalmente, proveniente do fornecedor de madeira serrada, e também por falta de inspeção mais rigorosa na chegada da madeira.

O desmembramento do Diagrama de Ishikawa em famílias (método 6M's) permitiu verificar, ainda, que existe

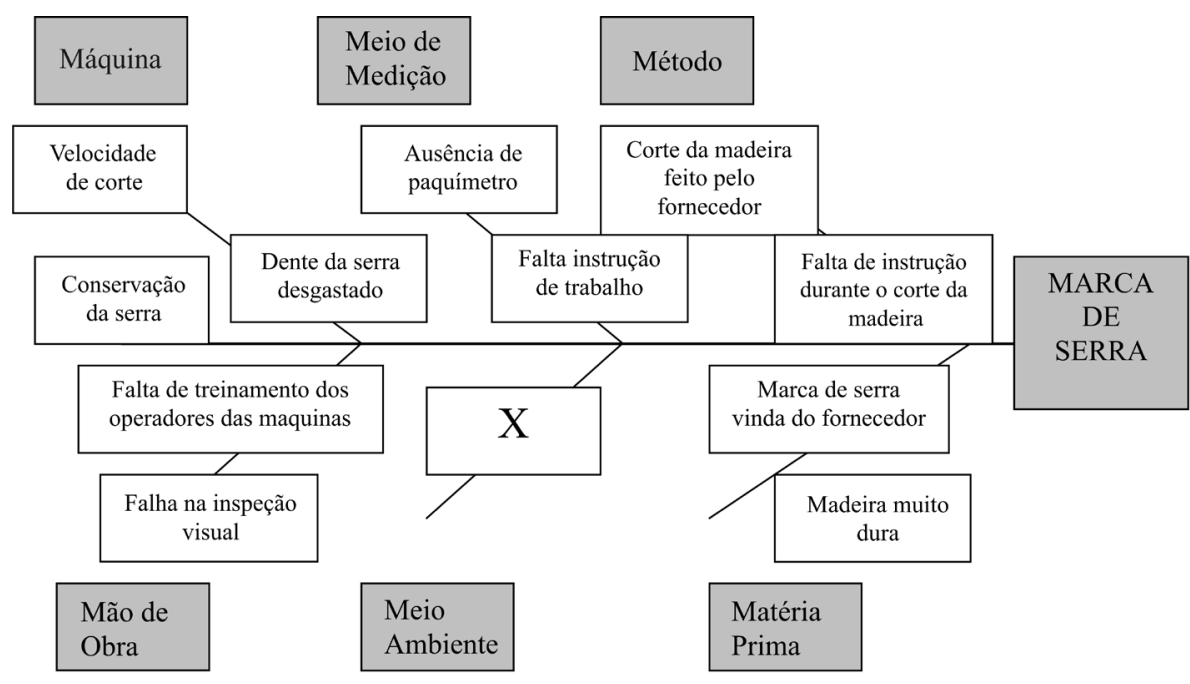

Figura 4 - Aplicação do Diagrama de Ishikawa para marca de serra. 


\begin{tabular}{|c|c|c|c|c|c|}
\hline $\begin{array}{l}0 \text { que fazer } \\
\text { (What) }\end{array}$ & $\begin{array}{c}\text { Onde } \\
\text { (Where) }\end{array}$ & $\begin{array}{l}\text { Por quê } \\
\text { (Why) }\end{array}$ & $\begin{array}{l}\text { Quando } \\
\text { (When) }\end{array}$ & $\begin{array}{l}\text { Quem } \\
\text { (Who) }\end{array}$ & $\begin{array}{l}\text { Como } \\
\text { (How) }\end{array}$ \\
\hline Inspeção mais rigorosa & $\begin{array}{l}\text { No setor de } \\
\text { recebimento da } \\
\text { madeira }\end{array}$ & $\begin{array}{c}\text { Para não deixar o } \\
\text { problema seguir mais } \\
\text { adiante }\end{array}$ & $\begin{array}{l}\text { A madeira chegar do } \\
\text { fornecedor }\end{array}$ & $\begin{array}{c}0 \text { responsável pelo setor } \\
\text { (Encarregado) }\end{array}$ & $\begin{array}{c}\text { Através de análise } \\
\text { visual }\end{array}$ \\
\hline $\begin{array}{l}\text { Aplainar mais a madeira } \\
\text { serrada }\end{array}$ & No setor de lamelas & $\begin{array}{l}\text { Para não haver tanta } \\
\text { perda de madeira com } \\
\text { marca de serra }\end{array}$ & $\begin{array}{l}\text { Toda vez que aparecer } \\
\text { madeira falhada nas } \\
\text { duas faces }\end{array}$ & $\begin{array}{l}0 \text { responsável do setor } \\
\text { (Encarregado) }\end{array}$ & $\begin{array}{l}\text { Na plaina (S4S), } \\
\text { aplainando mais as } \\
\text { faces da madeira }\end{array}$ \\
\hline Fazer apenas 4 lamelas & No setor de lamelas & $\begin{array}{l}\text { Para não haver tanta } \\
\text { perda com marca de } \\
\text { serra }\end{array}$ & $\begin{array}{c}\text { Toda vez que a } \\
\text { madeira aparecer } \\
\text { falhada nas duas } \\
\text { faces }\end{array}$ & $\begin{array}{l}0 \text { responsável do setor } \\
\text { (Encarregado) }\end{array}$ & $\begin{array}{c}\text { Na serra múltipla. } \\
\text { Produzindo apenas } 4 \\
\text { lamelas em vez de } 5 \\
\text { lamelas }\end{array}$ \\
\hline $\begin{array}{l}\text { Criar um alerta de } \\
\text { qualidade }\end{array}$ & $\begin{array}{l}\text { No setor de } \\
\text { recebimento de } \\
\text { madeira e no setor de } \\
\text { lamelas }\end{array}$ & $\begin{array}{c}\text { Para alertar os } \\
\text { funcionários dos defeito }\end{array}$ & $\begin{array}{l}\text { Toda vez que ocorrer } \\
\text { um grande numero de } \\
\text { marca de serra }\end{array}$ & $\begin{array}{c}0 \text { setor de qualidade da } \\
\text { empresa }\end{array}$ & $\begin{array}{c}\text { Através de alertas de } \\
\text { qualidade, com foto } \\
\text { do defeito e o tipo de } \\
\text { defeito }\end{array}$ \\
\hline
\end{tabular}

Tabela 1 - Problemas sugeridos no brainstorming para marca de serra.

\begin{tabular}{lcc}
\hline Defeitos & $\begin{array}{c}\mathrm{N}^{\circ} \text { de } \\
\text { ocorrências }\end{array}$ & $\%$ \\
\hline Marca de serra vindo do fornecedor & 4 & $31 \%$ \\
\hline Corte da madeira feita pelo fornecedor & 3 & $23 \%$ \\
\hline Falta de instrução de trabalho & 2 & $15 \%$ \\
\hline Falha na inspeção visual & 2 & $15 \%$ \\
Conservação da serra & 1 & $8 \%$ \\
\hline Dente da serra desgastado & 1 & $8 \%$ \\
\hline Ausência de paquímetro & 0 & $0 \%$ \\
\hline Falta de instrução durante o corte da madeira & 0 & $0 \%$ \\
Falta de treinamento dos operadores das maquinas & 0 & $0 \%$ \\
Velocidade de corte & 0 & $0 \%$ \\
Madeira muito dura & 0 & $0 \%$ \\
Somatório & 13 & $100 \%$ \\
\hline
\end{tabular}

falta de manutenção das máquinas evidenciado pelas causas : conservaçấo da serra e dente de serra desgastado. Existe, também uma falta de treinamento e organização na empresa evidenciados pelas causas falta de treinamento, falhas na inspeção, falta de paquímetro.

\section{PLANO DE AÇÃO}

A Tabela 2 representa graficamente o plano de ação " $5 \mathrm{~W}$ $2 \mathrm{H}$ " para a causa "MARCA DE SERRA", porém neste caso não está apresentado o $H O W M U C H$ (quanto custa) por se tratar aqui de uma informação confidencial.

Pretende-se com este Plano de Ação prevenir a reocorrência do defeito marca de serra, diminuindo desta forma os desclassificados e/ou refugos com a conseqüente otimização do processo de produção de lamelas para pisos engenheirados de madeira.

\section{CONCLUSÕES}

Com base nos estudos realizados neste trabalho as seguintes conclusôes podem ser apresentadas:
O defeito mais freqüente encontrado na produção de lamelas foi a marca de serra. As espécies que mais apresentaram a marca de serra foram: Amendoim (Pterogyne nitens Tul) e Timborana (Pseudopiptadenia suaveolens Miq);

- As principais causas para a ocorrência da marca de serra foram problemas operacionais do fornecedor relacionados à manutenção de serras; possivelmente com uma inspeção mais rigorosa, $80 \%$ dos problemas sejam solucionados;

- Os planos de ação proposto neste trabalho podem reduzir esse percentual de defeito, com melhoria da qualidade da madeira processada e redução de descartes na produçáo de lamelas, contribuindo para produçáo de piso de alta qualidade e livre de defeitos;

- Recomenda-se a realização de um estudo posterior para verificaçấo da eficácia da implementação dos planos de ação recomendados.

\section{BIBLIOGRAFIA CITADA}

Associação Brasileira da Indústria da Madeira Processada mecanicamente. 2007. Estudo Setorial 2007. Curitiba, 40 pp.

Bonduelle, G. 2007. Qualidade total na gestão florestal. Material didático do curso de especialização à distância em gestão florestal. Universidade Federal do Paraná, PECCA, Curitiba, 205 pp.

Iwakiri, S.; Stinghen, A.B.M.; Nunes, E.L.S.; Zamarian, E.H.C.; Adriazola, M.K.O. 2006. Utilização de lâminas de Eucalyptus grandis e Eucalyptus maculata como alternativas para produção de piso laminado com montagem direta. Floresta, 36: 425-430.

Juran, J M.; Gryna, F M. 1991. Controle de qualidade. Makron Books, São Paulo, 360 pp.

Sellers, T. 1993. Plywood and adhesive technology. Marcel Dekker, New York, 661 pp.

Tsoumis, G. 1991. Science and technology of wood: it'sstructure, properties and utilization. Van Nostrand Reinhold, New York, 494 pp.

Recebido em: 15/10/2008

Aceito em: 12/08/2009 